\title{
A Case of Patent Ductus Arteriosus in a 74-Year-Old Woman
}

\author{
Shin-ichiro Ohkawa, M.D., Keisuke Hiraoka, M.D., \\ Hiroyuki Shimada, M.D.,* and Masaya Sugiura, M.D.
}

\begin{abstract}
Summary
A case of patent ductus arteriosus in a 74-year-old female was presented, who was the oldest case reported in Japan. The ductus was funnelshaped, $15 \mathrm{~mm}$. in lenght, $9 \times 6 \mathrm{~mm}$. in size at the aortic opening between calcified and atheromatous plaques and had a membranous substance at the pulmonary opening.
\end{abstract}

\section{Additional Indexing Words:}

Congenital heart disease in the aged Patent ductus arteriosus in the aged Continuous murmur

QINCE Josefson ${ }^{1 /}$ had reported a case of patent ductus arteriosus (PDA) in $D$ a 66-year-old female in 1897, almost 24 cases of PDA in the elderly (over 60 years) have been reported in the literatures. ${ }^{1-9}{ }^{\text {) }}$ In this communication we presented a case of PDA in a 74-year-old woman, who was the oldest case in Japan.

\section{Case Report}

A 70-year-old woman (S.U.) entered the Tokyo Municipal Home for the Aged in 1965. Physical and laboratory examinations revealed a cancer of the stomach with some polyps, which was treated surgically. Postoperative course was uneventful until 3 years later, when she was noticed to have a continuous murmur at the precordium and admitted to the hospital for further evaluation of cardiac status.

The patient was thin and small, having neither edema nor anemia. Her blood pressure was $188 / 86 \mathrm{~mm} . \mathrm{Hg}$ and physical examination revealed an enlarged heart, and a systolic murmur (Levine 2/6) of ejection type at the apex and a continuous murmur (Levine 3/6) at the Erb's area and at the area 1 fingerbreadth lateral from the pulmonic area, having a machinery quality. Main laboratory data showed slight anemia (RBC: $297 \times 10^{4}, \mathrm{Hb}: 64 \%$ ) and slight liver damage (TTT: 5.2 , ZnTT: 12, CGLF: +++ ). Cardiac index, measured by dye dilution method was $3.1 \mathrm{~L} . / \mathrm{min} . / \mathrm{M}^{2}$ The electrocardiogram (Fig. la) showed left ventricular hypertrophy, and phonocardiogram showed a continuous murmur at the Erb's area

From the Department of Internal Medicine and *Department of Pathology, Yoiku-in Hospital, Tokyo Municipal Home for the Aged, Itabashi, Tokyo.

Received for publication April 13, 1971. 


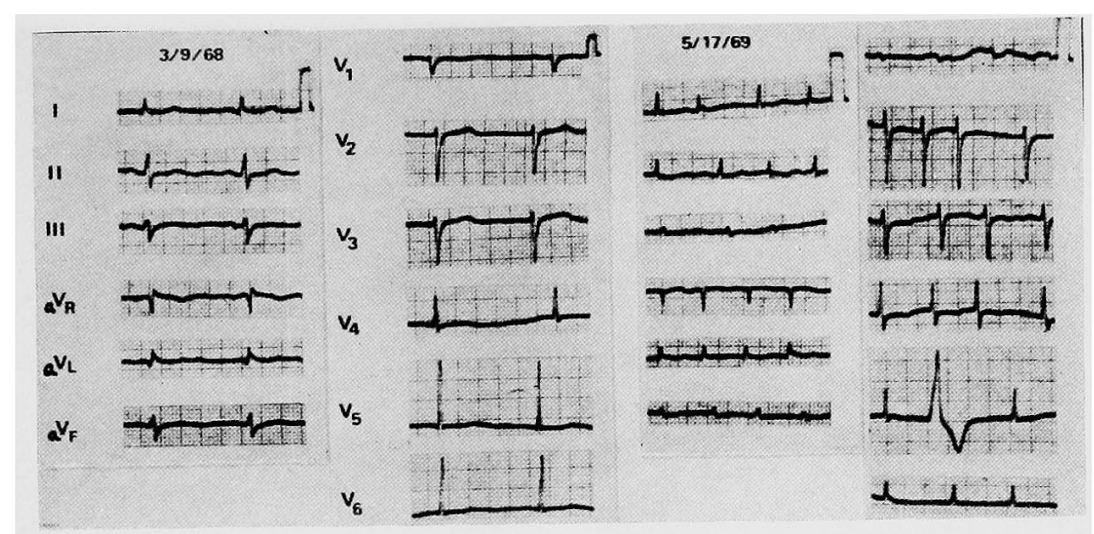

Fig. 1. Electrocardiograms showing normal sinus rhythm and left ventricular hypcrtrophy in (a) and atrial fibrillation in (b).

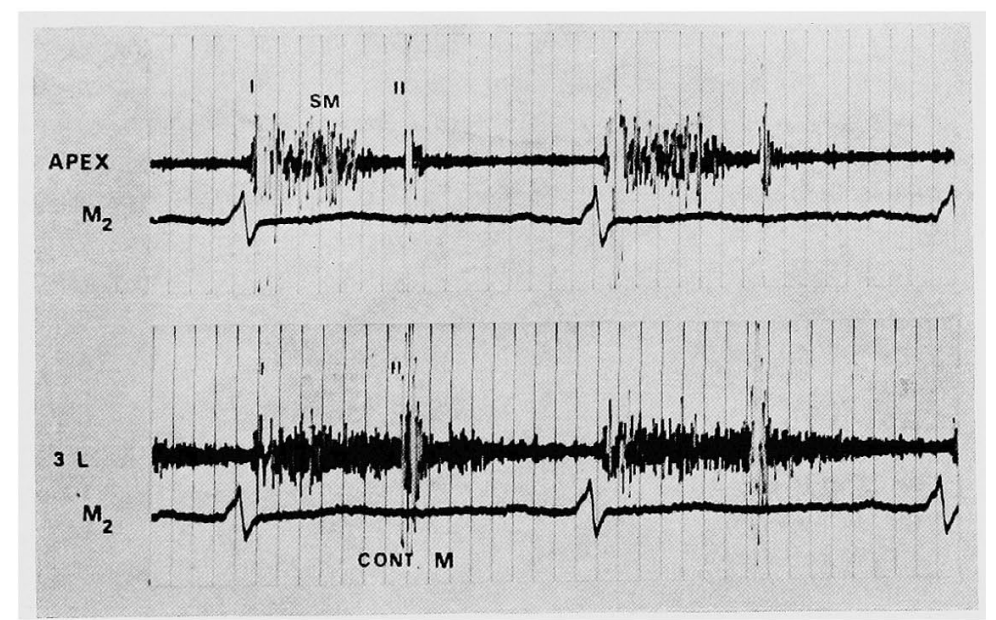

Fig. 2. Phonocardiogram recorded at the apex and the Erb's area, showing continuous murmur with an accentuated second sound.

(Fig. 2). X-ray film of the chest (Fig. 3a) revealed moderate cardiac enlargement and the presence of double calcified shadow in the aortic arch, which crossed each other. Retrograde aortography (Fig. 3b) revealed simultaneous filling of contrast material in both aortic and main pulmonary artery. A diagnosis of PDA was made, after a possibility of aortico-pulmonary window was ruled out by its extreme rarity in aged people. She was followed up at the out-patient clinic until 14 months later, when she was readmitted to the hospital, with complaints of edema and shortness of breath on exertion. Physical examination showed a rapid irregular pulse, moist rales in the bilateral lung fields, and liver was palpable by 1 fingerbreadth under the right costal margin. Electrocardiogram (Fib. 1b) showed atrial fibrillation. The continuous murmur at the base was still audible with somewhat decreased intensity. Diagnosis of congestive heart failure and atrial fibrillation was made and treatment was started with digitalis and diuretics. Congestive heart 

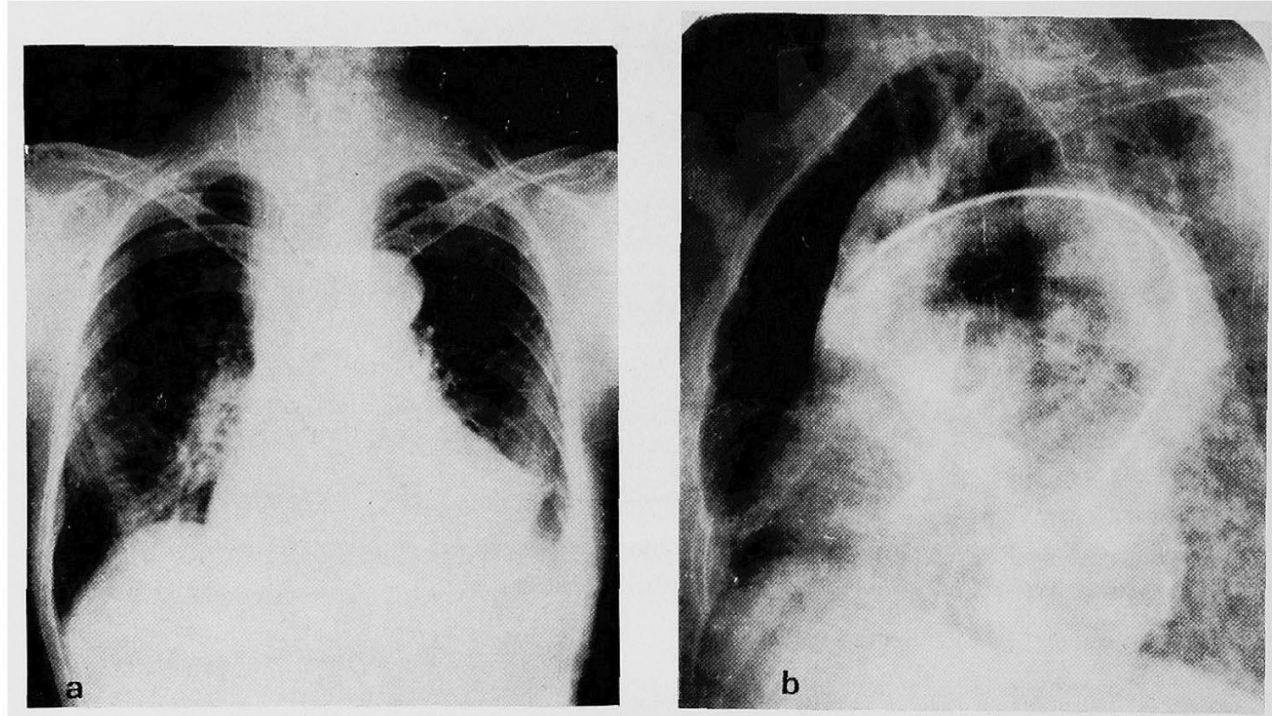

Fig. 3. (a) X-ray film of the chest demonstrating moderate cardiac enlargement and calcification of the aortic arch. (b) Angiocardiogram obtained by the retrograde catheterization of the aorta. Contrast material injected at the root of the aorta was filled in the main trunk of the pulmonary artery and left pulmonary artery at the same time.

failure was refractory to the therapy and she fell into coma and died in September, 1969.

Autopsy was performed, which showed a heart weight of $410 \mathrm{Gm}$., with marked dilatation of right ventricle, pulmonary artery, left atrium, and left ventricle. In the aortic arch, a funnel-shaped orifice $(9.2 \times 6.0 \mathrm{~mm}$.) was found $5 \mathrm{~mm}$. distal from an atheromatous area $(15 \mathrm{~mm}$. in diameter) at the level of the left subclavian artery (Fig. 4a, c). This was aortic opening of the PDA, which was connected with the main branch of the left pulmonary artery with its length of $15 \mathrm{~mm}$. (Fig. 4b). The pulmonary opening of PDA (Fig. 4d) was formed by a membranous bulging which had double slit-like openings of $4 \mathrm{~mm}$. and $2 \mathrm{~mm}$. in length (Fig. $4 \mathrm{~d}$ ). Transverse section of the ductus showed that the aortic opening was surrounded by the atheromatous and calcified plaques (Fig. 5a). The ductus had some fibroelastosis in the wall, but intima and media were relatively thin. Membranous tissue at the pulmonary end of the ductus was fibroelastic and continuous to the intima of the pulmonary artery. A part of it showed a myxomatous loose connective tissue (Fig. 5b). There was not any jet lesion in the pulmonary artery, except of its swollen media (Fig. 5d). The wall of left atrium and pulmonary vein showed endocardial fibroelastosis, suggesting a continued flow effect during life (Fig. 5c). Other organs showed chronic congestion especially in the liver and kidneys and pleural effusion at the left side. 


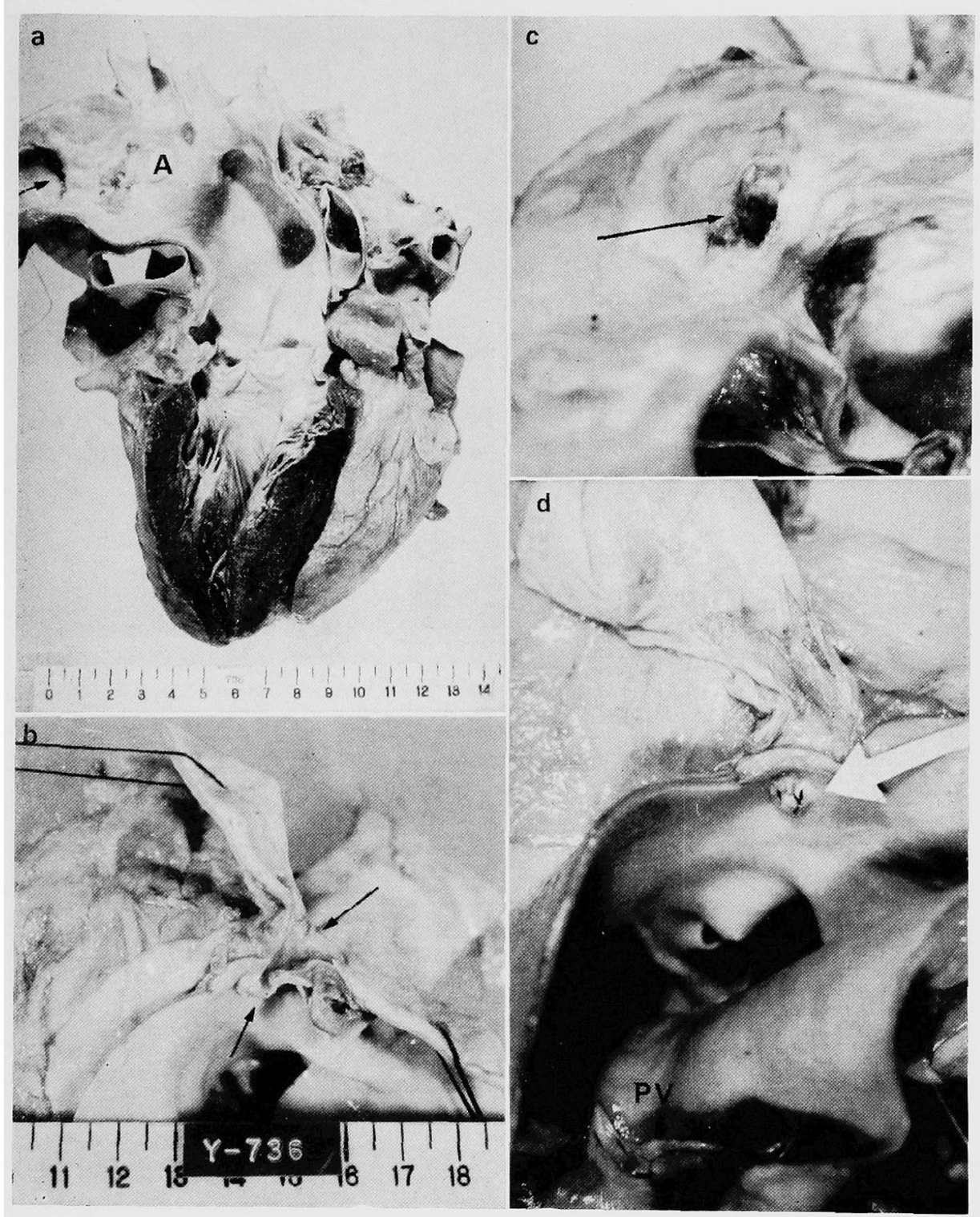

Fig. 4. The heart and ductus. (a) The left ventricle was opened usually but the aorta was opened from the posterior wall to demonstrate the ductus (arrow). At the level of the left subclavian artery there was a large atheromatous plaque (marked A). The orifice to the patent ductus was located $1 \mathrm{~cm}$. distal of atheroma. (b) Longitudinal cut surface of the ductus with the aortic orifice (upper arrow) and the pulmonary orifice (lower arrow). (c) Aortic orifice (arrow). (d) Pulmonary orifice (white arrow) with 2 slit-like apertures in the membranous structure. PV indicates pulmonary valves. 


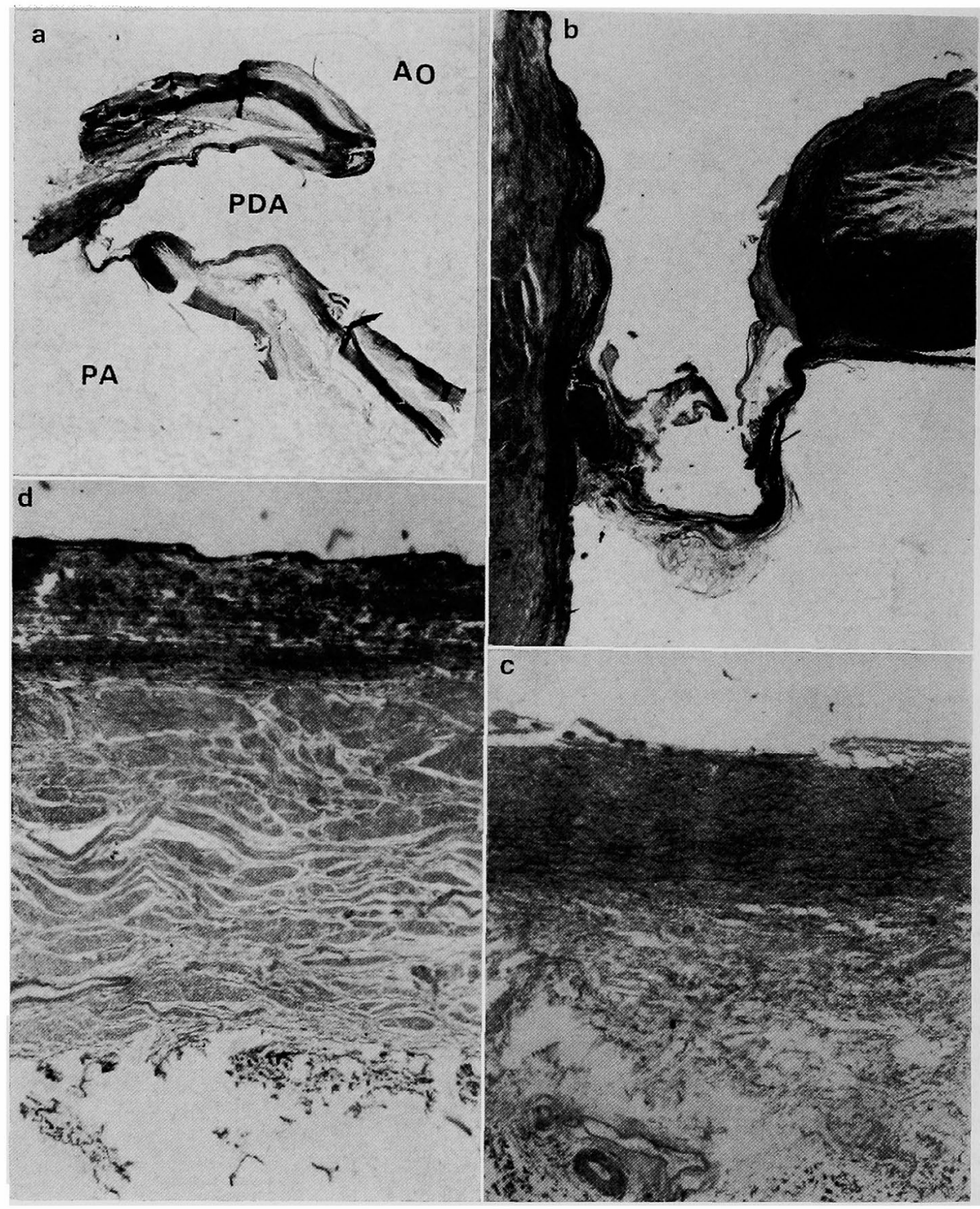

Fig. 5. Histological findings. (a) Longitudinal section of the PDA, which showed the funnel shape with wide aortic orifice and narrow pulmonary orifice. Edge of the aortic orifice was outlined by calcification. At the pulmonary orifice, there was the membranous structure (E. v. G. stain $\times 1$ ). (b) Magnified area of this structure showing the myxomatous tissues (E. v. G. $\times 13$ ). (c) Left atrium showing the fibroelastic tissue at the endocardium (E. v. G. $\times 40$ ). (d) fibroelastosis and the medial hypertrophy of the pulmonary artery (E. v. G. $\times 40$ ). 


\section{Discussion}

Even though congenital heart disease of the aged ${ }^{10)-14)}$ is generally considered to be rare, several case reports of atrial septal defect, ventricular septal defect or more rarely PDA have been sporadically found. Concerning with the PDA in the aged, ${ }^{1-9)}$ approximately 24 cases have been reported. Only 3 cases were male among them. The oldest case was a 90 -year-old male. ${ }^{9}$ ) In our country 2 cases were reported previously ; one was a 60-year-old woman? and the other was a 65 -year-old woman, ${ }^{8}$ ) of which the latter was unfortunately not autopsied.

Edwards ${ }^{15}$ proposed an anatomical classification of PDA as cylindrical, funnel and window types. In this case the aortic opening was $96 \mathrm{~mm}$., and the pulmonary opening was slit-like, which could be classified as the funnel type. The calcification around the aortic opening of PDA suggests hemodynamic effects on the ridge of the funnel by the turbulant blood flow which would have streamed into the ductus. Membranous substance at the pulmonary opening was a peculiar structure and not clear in its mechanism of formation. Morphological similarity was found in a case of 85-year-old female, reported by Bain, ${ }^{3}$ in whom the aortic opening was associated with calcification and the pulmonary opening had a surrounding membranous fringe like that of our case, but he did not mention the histological nature of this structure nor the mechanism of its formation. In our case the structure was fibroelastic tissue which developed from the intima of the pulmonary artery. These facts strongly suggest a possibility as a tendency of spontaneous closure of PDA. Keys $^{2}$ summarized 67 cases of PDA in adults (over 17 years), and emphasized that short ductus and the presence of atheromatous and calcified plaques in the pulmonary artery were common. In our case changes of the pulmonary artery were not detected and the length of the ductus was $15 \mathrm{~mm}$., which was not extremely short. Absence of jet lesion and atheroma in the pulmonary artery could be explained by a sprinkler effect by the membranous structure at the pulmonary orifice of the ductus. Dilatation of the right ventricle, pulmonary artery, left atrium and left ventricle, and fibroelastosis of the endocardial layers suggest the long-lasting and increased flow effects in these chambers.

The reason of long survival in this case might be the facts that she was away from bacterial endocarditis and she could have tolerated to the left-toright shunt till the terminal attack of congestive heart failure with atrial fibrillation, as reflected by the lower normal limit of cardiac index. 


\section{REFERENCES}

1. Josefson, A.: Nord. Med. Ark. (No. 17, 1897.) (Abstract in Gblt. inn. Med. 19: 634, 1898.)

2. Keys, A. and Shapiro, M. J.: Am. Heart J. 25: 158, 1943.

3. Bain, C. W. C.: Brit. Heart J. 14: 276, 1951.

4. Boe, J. and Humerfelt, S.: Acta Med. Scand. 167: 73, 1960.

5. Heino, A. E.: Ann. Med. Intern. Fenn. 52: 143, 1963.

6. Calne, D. B. and Raftery, F. B.: Brit. Heart J. 28: 716, 1966.

7. Tohgi, H., et al.: Jap. Heart J. 8: 94, 1967.

8. Uruga, K., et al.: Tohoku Med. J. 76: 117, 1968 (in Japanese).

9. White, P. D., et al.: New Engl. J. Med. 280: 146, 1969.

10. Burch, G. E.: Am. Heart J. 78: 700, 1969.

11. Fisher, J. M., et al.: Circulation 25: 821, 1962.

12. Mark, H. and Young, D.: Am. J. Cardiol. 15: 293, 1965.

13. Rokseth, R.: Acta Med. Scand. 183: 131, 1968.

14. Ueda, H., et al.: Rynsho-Kagaku 4: 14, 1968 (in Japanese).

15. Gould, S. E.: Pathology of the heart, 2nd ed., Charles C. Thomas Publ., Springfield, Illinois, p. 438,1960 . 